\title{
Effect of denosumab on bone mineral density in Japanese women with osteopenia treated with aromatase inhibitors for breast cancer: subgroup analyses of a Phase II study
}

This article was published in the following Dove Press journal:

Therapeutics and Clinical Risk Management

\author{
Katsuhiko Nakatsukasa' \\ Hiroshi Koyama ${ }^{2}$ \\ Yoshimi Ouchi' \\ Kouichi Sakaguchi' \\ Yoshifumi Fujita' \\ Takayuki Matsuda ${ }^{3}$ \\ Makoto Kato ${ }^{4}$ \\ Eiichi Konishi ${ }^{5}$ \\ Tetsuya Taguchi' \\ 'Department of Endocrine and \\ Breast Surgery, Kyoto Prefectural \\ University of Medicine, Kyoto, Japan; \\ ${ }^{2}$ Department of Breast Surgery, \\ Nara City Hospital, Nara, Japan; \\ ${ }^{3}$ Department of Breast Surgery, \\ Saiseikai Kyoto Hospital, Kyoto, Japan; \\ ${ }^{4}$ Department of Breast Surgery, Kato \\ Breast Surgery Clinic, Kyoto, Japan; \\ ${ }^{5}$ Department of Surgical Pathology, \\ Kyoto Prefectural University of \\ Medicine, Kyoto, Japan
}

Correspondence: Katsuhiko Nakatsukasa Department of Endocrine and Breast Surgery, Kyoto Prefectural University of Medicine, 465 Kajii-cho, Kawaramachi-hirokoji, Kamigyo-ku,

Kyoto 602-8566, Japan

Tel +8I 7525 I 5534

Fax +8I 75 25। 0270

Email kacchan@koto.kpu-m.ac.jp
Background: The aim of the study was to conduct subgroup analyses of therapeutic effects of 12-month denosumab therapy on the percentage change in bone mineral density (BMD) from baseline in the lumber spine and femoral neck.

Materials and methods: We prospectively evaluated the BMD of the lumbar spine and femoral neck of 100 hormone receptor-positive, clinical stage I-IIIA postoperative postmenopausal breast cancer patients, for whom treatment with aromatase inhibitors (AIs) as adjuvant endocrine therapy was scheduled. The primary endpoint was the percent change in lumbar spine BMD from baseline to 12 months. Patient subgroups were analyzed according to baseline variables that are known risk factors for bone loss, including previous AI therapy, age, time since menopause, baseline body mass index (BMI), and baseline BMD T-score.

Results: At 12 months, lumbar spine BMD increased by 4.7\%; the patients who were administered AI therapy prior to denosumab $(n=70)$ demonstrated a $4.7 \%$ increase in BMD, and the patients who received denosumab at the start of AI therapy $(n=30)$ demonstrated a $4.5 \%$ increase in BMD $(p=0.8385)$. Additionally, $2.4 \%$ and $1.4 \%$ increases in BMD of the right and left femoral neck, respectively, were observed. Initiation of AI (with denosumab, before denosumab), type of AI (non-steroidal, steroidal), age ( $<65, \geq 65$ years), time since menopause ( $\leq 5,>5$ years), BMI $\left(<25, \geq 25 \mathrm{~kg} / \mathrm{m}^{2}\right)$, and T-score $(\leq-1.0,>-1.0)$ of the right femoral neck were as follows: $(2.2 \%, 2.5 \%, p=0.7773),(2.6 \%, 0.9 \%, p=0.1726),(2.5 \%, 2.3 \%, p=0.7594)$, $(2.1 \%, 2.4 \%, p=0.2034),(2.1 \%, 2.9 \%, p=0.2034)$, and $(2.3 \%, 2.7 \%, p=0.6823)$, respectively. Initiation of AI (with denosumab, before denosumab), type of AI (non-steroidal, steroidal), age ( $<65, \geq 65$ years), time since menopause ( $\leq 5,>5$ years), BMI $\left(<25, \geq 25 \mathrm{~kg} / \mathrm{m}^{2}\right)$, and T-score $(\leq-1.0,>-1.0)$ of the left femoral neck were as follows: $(1.0 \%, 1.5 \%, p=0.1972),(1.2 \%, 2.7 \%$, $p=0.2931),(1.4 \%, 1.3 \%, p=0.8817),(-0.1 \%, 1.6 \%, p=0.1766),(1.3 \%, 1.9 \%, p=0.6465)$, and $(1.5 \%, 1.1 \%, p=0.6573)$, respectively.

Conclusion: Twice-yearly treatment with denosumab was associated with increased BMD among Japanese women receiving adjuvant AI therapy, regardless of the baseline characteristics or skeletal site.

Keywords: aromatase inhibitor, denosumab

\section{Introduction}

Several large clinical trials have shown that, compared with tamoxifen, third-generation aromatase inhibitors (AIs) administered either alone or sequentially after 2-3 years of tamoxifen treatment for hormone receptor-positive breast cancer in postmenopausal 
women resulted in a longer disease-free survival and fewer endometrial and thromboembolic adverse events. ${ }^{1-6}$ Therefore, AIs are widely used by patients with postmenopausal breast cancer as a first-line adjuvant hormonal therapy. AIs inhibit the conversion of androgens to estrogens, resulting in a significant decline in estrogen levels, which in turn leads to lower bone mineral density (BMD). Moreover, several studies have reported that the BMD loss observed in postmenopausal breast cancer patients receiving long-term AIs is twice that observed in normal postmenopausal women of the same age. ${ }^{46}$ Therefore, patients receiving AIs are at increased risk for bone fracture, which can reduce their quality of life..$^{7,8}$ Efforts to prevent BMD loss are thus needed.

We previously reported the results of a 12-month, nonrandomized prospective study, which demonstrated that denosumab, a fully human monoclonal antibody against receptor activator of nuclear-factor kappa-B ligand, increased BMD in the lumbar spine and femoral neck in patients with hormone receptor-positive breast cancer who were receiving adjuvant $\mathrm{AI}$ therapy and demonstrated evidence of low bone mass. ${ }^{9}$ Thus far in Japan, the efficacy of denosumab in the treatment of AI-associated bone loss has not been evaluated in a prospective study. Moreover, it is important to evaluate the outcomes of denosumab according to baseline and disease characteristics, to identify patients who might yield more benefits from receiving denosumab and those who would not. Patient subgroups were analyzed according to baseline variables that are known risk factors for bone loss, including previous AI therapy, age, time since menopause, baseline body mass index (BMI), and baseline BMD T-score. Herein, we present the results of these subgroup analyses of the therapeutic effects of 12-month denosumab therapy on the percentage change in BMD from baseline in the lumber spine and femoral neck.

\section{Materials and methods}

\section{Patients}

Complete inclusion and exclusion criteria have been described previously. Briefly, data for postmenopausal women with early stage, histologically confirmed, hormone receptor-positive invasive breast cancer who were scheduled to receive AIs as adjuvant endocrine therapy or were in the process of receiving AI adjuvant therapy were included for analysis. The inclusion criteria also included completion of the chemotherapy regimen $\geq 4$ weeks before study entry and evidence of low bone mass (lumbar spine, right femoral neck, and left femoral neck BMD corresponding to a T-score classification of -1.0 to -2.5$)$. Key exclusion criteria included osteoporosis (T-score $<-2.5$ ), prior vertebral diseases, and current active dental problems including infection of the teeth or jawbone.

\section{Study design}

This non-randomized prospective study was conducted at 3 institutions in Japan. Patients were scheduled to receive $60 \mathrm{mg}$ denosumab subcutaneously every 6 months. All patients were prescribed calcium (1 g/day) and vitamin D ( $\geq 400 \mathrm{IU} /$ day). No change in AI therapy was mandated upon study participation. Approvals from appropriate research ethics committees were obtained for each participating study center. All patients provided written informed consent before participating. The study was approved by the Institutional Review Board of Kyoto Prefectural University of Medicine on August 2, 2013, and conducted in accordance with the Helsinki Declaration of 1975, as revised in 1983. This study was registered with the UMIN Clinical Trial Registry (UMIN-CTR, UMIN000027425). All procedures performed in studies involving human participants were in accordance with the ethical standards of the institutional and/or national research committee and with the 1964 Helsinki declaration and its later amendments or comparable ethical standards.

\section{Subgroup analyses}

Analyses of the percentage change in BMD from baseline in the lumbar spine and femoral neck at 12 months were conducted in the following subgroups of patients: start of AI therapy (with denosumab, before denosumab), type of AI therapy (steroidal, non-steroidal), age ( $<65, \geq 65$ years), time since menopause $(\leq 5,>5$ years), baseline BMI $\left(<20, \geq 20 \mathrm{~kg} / \mathrm{m}^{2}\right)$, and BMD $(-2.5<\mathrm{T}$-score $<-1.0$, $\mathrm{T}$-score $\geq-1.0)$. Subgroup analyses for the primary endpoint involved a post hoc analysis.

\section{Statistical analysis}

A sample size of 74 patients was calculated to achieve a statistical power of $80 \%$ and to detect a $4 \%$ difference in the percent change in lumbar spine (L1-L4) BMD from baseline to 12 months. To allow for a $20 \%$ dropout rate, at least 90 patients were required. Paired $t$-tests were used to compare the two groups. $p$-values reported were based on a two-sided comparison. A $p$-value $\leq 0.05$ was considered statistically significant. All statistical analyses were performed using JMP software version 12.

\section{Results}

A complete description of the baseline disease characteristics and disposition has been reported. The mean age (range) was 64 (54-89) years. A total of 103 patients were enrolled 
Table I Summary of baseline variables

\begin{tabular}{ll}
\hline Variable & $\begin{array}{l}\text { Denosumab } \\
(\mathbf{n}=\mathbf{1 0 0})\end{array}$ \\
\hline $\begin{array}{l}\text { Start of Al therapy, } \mathrm{n}(\%) \\
\quad \text { With denosumab }\end{array}$ & 30 \\
$\quad$ Before denosumab & 70 \\
Type of Al therapy, $\mathrm{n}(\%)$ & 89 \\
$\quad$ Non-steroidal & $1 \mathrm{I}$ \\
$\quad$ Steroidal & \\
Age, $\mathrm{n}(\%)$ & $5 \mathrm{I}$ \\
$\quad<65$ years & 49 \\
$\geq 65$ years & \\
Time since last menstrual cycle, $\mathrm{n}(\%)$ & 13 \\
$\quad \leq 5$ years & 87 \\
$>5$ years & \\
Body mass index (kg/m²), $\mathrm{n}(\%)$ & 76 \\
$\quad<25$ & 24 \\
$\quad \geq 25$ & \\
Lumbar spine BMD T-score, $\mathrm{n}(\%)$ & 53 \\
$\leq-1.0$ & 47 \\
$>-1.0$ & 62 \\
Right femoral neck BMD T-score, $\mathrm{n}(\%)$ & 38 \\
$\leq-1.0$ & 36 \\
$>-1.0$ & \\
Left femoral neck BMD T-score, $\mathrm{n}(\%)$ & \\
$\leq-1.0$ & \\
$>-1.0$ & \\
\hline
\end{tabular}

Abbreviations: $\mathrm{Al}$, aromatase inhibitor; $\mathrm{BMD}$, bone mineral density.

and received denosumab thrice, at 0, 6, and 12 months. All patients were included in the subgroup analyses. We found that $30 \%$ of patients received denosumab at the start of AI therapy and $89 \%$ of patients received non-steroidal AI therapy (anastrozole or letrozole); the other patients received steroidal AI therapy (exemestane). Moreover, $51.0 \%$ of patients were aged $<65$ years and $87.0 \%$ patients had been postmenopausal for longer than 5 years (Table 1).

\section{BMD}

The percentage change in the lumbar spine BMD from baseline $( \pm 95 \% \mathrm{CI})$ over 12 months in the patients who received AIs with denosumab and those who received AIs before denosumab is shown in Figure 1. At 12 months, the patients who were administered AI therapy prior to denosumab $(\mathrm{n}=70)$ demonstrated a $4.7 \%$ increase in $\mathrm{BMD}$, and the patients who received denosumab at the start of AI therapy $(n=30)$ demonstrated a $4.5 \%$ increase in BMD.

The percentage change in BMD in the right femoral neck from baseline ( $\pm 95 \% \mathrm{CI})$ over 12 months in the patients who received AIs with denosumab and those who received AIs before denosumab is shown in Figure 2. At 12 months, the patients who were administered AI therapy prior to denosumab demonstrated a $2.2 \%$ increase in $\mathrm{BMD}$, and the patients who received denosumab at the start of AI therapy demonstrated a $2.5 \%$ increase in BMD. The percentage change in BMD in the left femoral neck from baseline $( \pm 95 \% \mathrm{CI})$ over 12 months in the patients who received AIs with denosumab and those who received AIs before denosumab is shown in Figure 3. At 12 months, the patients who were administered AI therapy prior to denosumab demonstrated a $1.5 \%$ increase in BMD, and the patients who received denosumab at the start of AI therapy demonstrated a $1.0 \%$ increase in BMD. The BMD of patients administered AIs before denosumab showed a greater increase, but without statistical significance.

Subgroup analyses of the treatment effects of denosumab at 12 months (least squares mean percentage difference [ $95 \%$ CI]) are shown in Table 2.

\section{Fractures}

At month 12, no non-traumatic clinical fractures occurred in patients receiving AI therapy and denosumab.

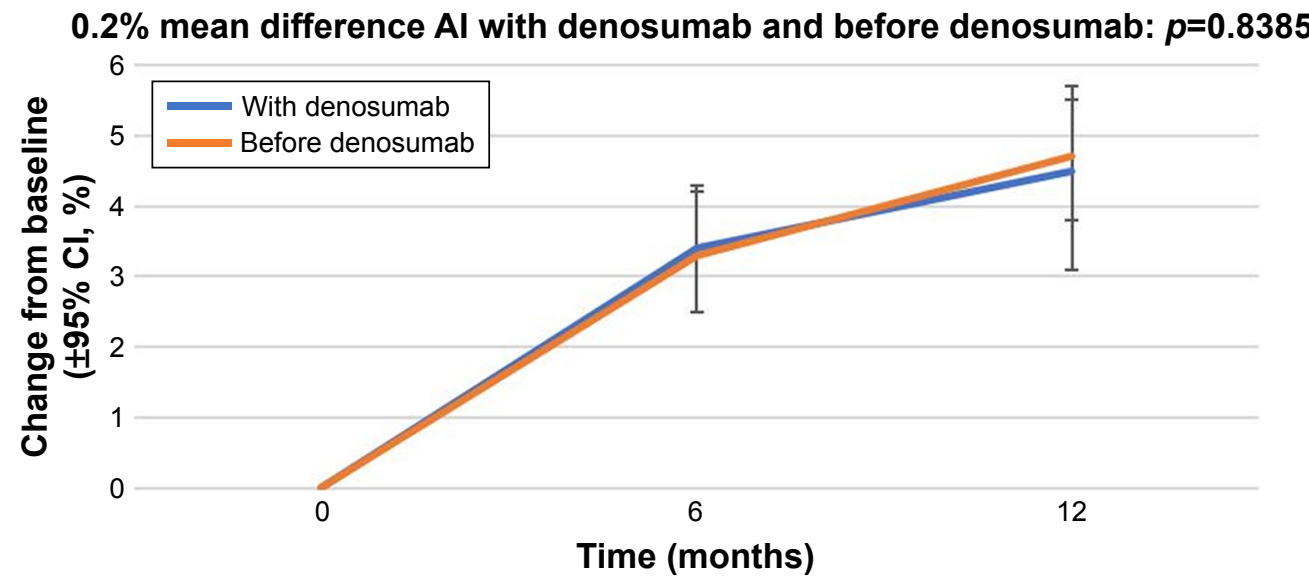

Figure I Percentage change in bone mineral density in the lumbar spine from baseline $( \pm 95 \% \mathrm{Cl})$ over $\mathrm{I} 2$ months in patients who started receiving Als with denosumab ("With denosumab") and those who had received Al before the initiation of denosumab therapy ("Before denosumab").

Abbreviation: Als, aromatase inhibitors. 


\section{3 mean difference $\mathrm{Al}$ with denosumab and before denosumab: $\boldsymbol{p}=\mathbf{0 . 7 7 7 3}$}

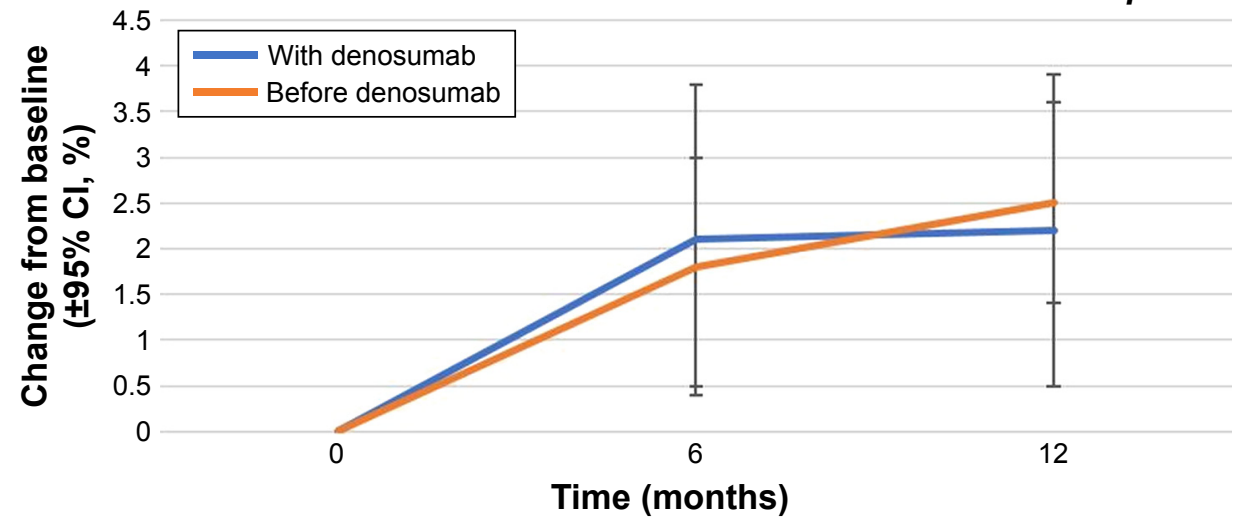

Figure 2 Percentage change in bone mineral density in the right femoral neck from baseline $( \pm 95 \% \mathrm{Cl})$ over 12 months in patients who started receiving Als with denosumab ("With denosumab") and those who had received Al before the initiation of denosumab therapy ("Before denosumab").

Abbreviation: Als, aromatase inhibitors.

\section{Discussion}

The increased risk for bone loss and fracture in breast cancer patients has become more evident following the use of AIs as adjuvant therapy. AI-induced bone loss occurs at more than twice the rate of physiologic postmenopausal bone loss. ${ }^{10}$ AI-associated bone loss continues throughout the duration of therapy, at an average rate of $2 \%$ per year. ${ }^{10,11}$ It is estimated that $>30 \%$ of patients treated with an AI will be diagnosed with osteoporosis in the subsequent years. ${ }^{12}$ The negative effect of estrogen depletion on bone appears to be associated with both steroidal and non-steroidal AIs, ${ }^{13,14}$ although the former could induce less bone loss. The prevention of AI-induced bone loss has been the subject of discussions at the American Society of Clinical Oncology, the National Osteoporosis Foundation, and the American Association of Clinical Endocrinologists, all of which have published guidelines and recommendations. ${ }^{15-18}$

A Japanese study revealed that the survival rate after hip fracture decreased dramatically over 2 years and the mortality risk remained high for 10 years. ${ }^{19}$ This mortality risk was approximately double that of the general population, even at 10 years after hip fracture.

Therefore, a therapeutic approach that could prevent AI-induced bone loss and increase the BMD of the femoral necks is needed. The primary analysis of this study showed that denosumab was an effective agent for the management of such bone loss. Next, it was important to determine whether the overall benefit of denosumab treatment was influenced by baseline variables that are known risk factors for bone loss. The most notable fracture risk factors include advancing age ( $>65$ years), AI therapy, chemotherapy-induced menopause, low BMI $\left(<20 \mathrm{~kg} / \mathrm{m}^{2}\right)$, a family history of hip fracture, a personal history of fragility fracture, corticosteroid use, excessive alcohol consumption, and smoking. ${ }^{20,21}$

$\mathrm{AI}$ is associated with accelerated bone loss; therefore, if AI therapy has already been administered, there exists the possibility of reducing the effects of denosumab. In other

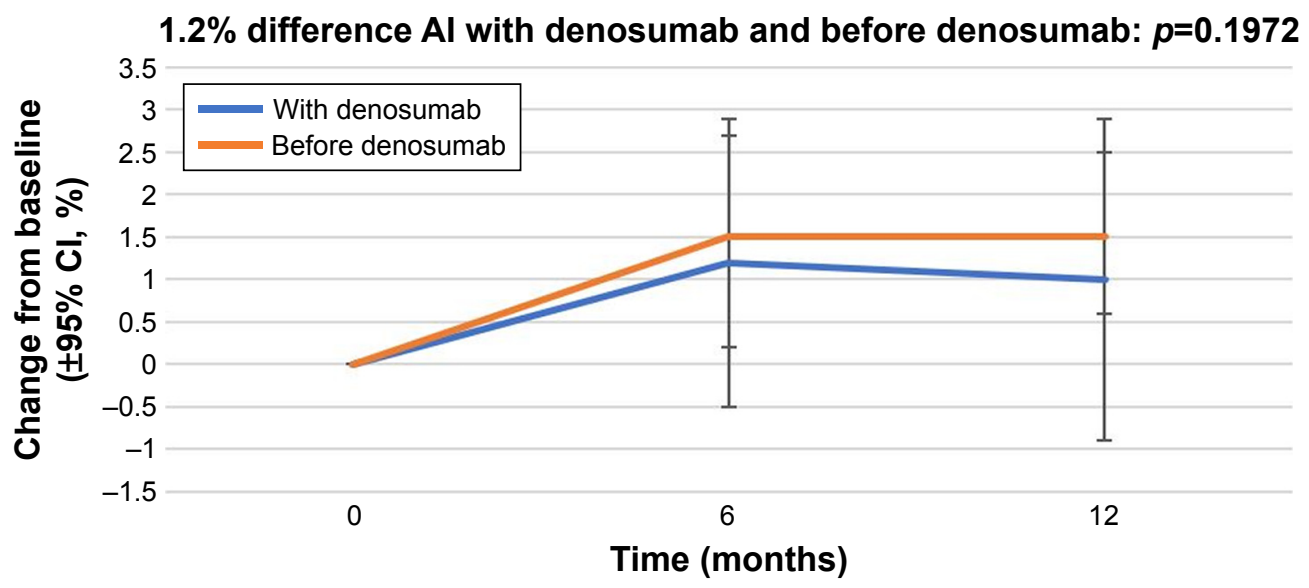

Figure 3 Percentage change in BMD in the left femoral neck from baseline ( $\pm 95 \% \mathrm{Cl}$ ) over 12 months in patients who started receiving Als with denosumab ("With denosumab") and those who had received Al before the initiation of denosumab therapy ("Before denosumab").

Abbreviations: Al, aromatase inhibitor; BMD, bone mineral density. 
Table 2 Subgroup analyses of the therapeutic effects of denosumab at 12 months

\begin{tabular}{|c|c|c|c|}
\hline & Lumbar spine & Right femoral neck & Left femoral neck \\
\hline \multicolumn{4}{|l|}{ Start of Al therapy $(n)$} \\
\hline With denosumab (30) & $4.5(3.1,5.8)$ & $2.2(0.5,3.9)$ & $1.0(-0.8,2.9)$ \\
\hline Before denosumab (70) & $4.7(3.8,5.7)$ & $2.5(1.4,3.6)$ & $1.5(0.6,2.5)$ \\
\hline$p$-value & 0.8385 & 0.7773 & 0.1972 \\
\hline \multicolumn{4}{|l|}{ Type of Al therapy (n) } \\
\hline Non-steroidal (89) & $5.0(4.2,5.8)$ & $2.6(1.7,3.5)$ & $1.2(0.3,2.2)$ \\
\hline Steroidal (II) & $2.1(-0.1,4.2)$ & $0.9(-3.4,5.3)$ & $2.7(0.9,4.4)$ \\
\hline$p$-value & $0.0085^{*}$ & 0.1726 & 0.2931 \\
\hline \multicolumn{4}{|l|}{ Age (n) } \\
\hline$<65$ years $(5 \mathrm{I})$ & $4.5(3.4,5.6)$ & $2.5(1.3,3.8)$ & $1.4(0.3,2.5)$ \\
\hline$\geq 65$ years $(49)$ & $4.9(3.8,5.9)$ & $2.3(0.9,3.7)$ & $1.3(0.0,2.6)$ \\
\hline$p$-value & 0.6306 & 0.7594 & 0.8817 \\
\hline \multicolumn{4}{|l|}{ Time since menopause (n) } \\
\hline$\leq 5$ years $(13)$ & $4.6(2.6,6.6)$ & $2.1(-0.4,4.6)$ & $-0.1(-2.5,2.2)$ \\
\hline$>5$ years $(87)$ & $4.7(3.8,5.5)$ & $2.4(1.4,3.4)$ & I.6 $(0.7,2.5)$ \\
\hline$p$-value & 0.9294 & 0.2034 & 0.1766 \\
\hline \multicolumn{4}{|l|}{ Body mass index $\left(\mathrm{kg} / \mathrm{m}^{2}\right)(\mathrm{n})$} \\
\hline$<25(76)$ & $4.9(4.0,5.7)$ & $2.1(1.1,3.1)$ & $1.3(0.3,2.2)$ \\
\hline$\geq 25$ (24) & $4.6(3.0,6.1)$ & $2.9(0.8,4.9)$ & $1.9(0.2,3.7)$ \\
\hline$p$-value & 0.5867 & 0.2034 & 0.6465 \\
\hline \multicolumn{4}{|l|}{ T-score } \\
\hline$\leq-1.0$ & $4.9(4.0,5.8)$ & $2.3(1.2,3.3)$ & $1.5(0.3,2.7)$ \\
\hline$>-1.0$ & $4.4(3.1,5.7)$ & $2.7(0.9,4.4)$ & I.I $(0.0,2.3)$ \\
\hline$p$-value & 0.6678 & 0.6823 & 0.6573 \\
\hline
\end{tabular}

Notes: Data are shown as the least squares mean percentage difference $(95 \% \mathrm{Cl}) .{ }^{*} p<0.05$.

Abbreviation: $\mathrm{Al}$, aromatase inhibitor.

words, the effect of denosumab becomes weak if the treatment period for AI is prolonged. In our trial, we showed that BMD at all skeletal sites similarly increased regardless of prior AI therapy. Age alone is among the strongest predictors of fracture. Because age significantly increases the risk for osteoporosis and fracture, ${ }^{22}$ it is imperative to understand the contribution of denosumab to that risk in women aged $\geq 65$ years. In our trial, we found that the BMD at all skeletal sites was similarly increased among patients aged $<65$ years and those aged $\geq 65$ years. In general, low BMI in both men and women correlates with an increased age-adjusted risk for any type of fracture, whereas high BMI values decrease the risk for fracture..$^{23}$ In our trial, we revealed that BMD at all skeletal sites similarly increased among BMI $<25 \mathrm{~kg} / \mathrm{m}^{2}$ and $\mathrm{BMI} \geq 25 \mathrm{~kg} / \mathrm{m}^{2}$ groups.

Anastrozole and letrozole are non-steroidal inhibitors, whereas exemestane is a steroidal inhibitor of the aromatase enzyme, which converts androgens into estrogens. The decrease in BMD has been shown to be lower in patients treated with exemestane, possibly owing to its steroidal structure. ${ }^{24}$ However, we observed the opposite for the lumber spine and right femoral neck, possibly owing to the small number of patients. In general, the lower the baseline BMD, the lower it will remain after 5 years of hormone therapy. ${ }^{25}$
Our trial revealed the BMD at all skeletal sites was similarly increased among those with a T-score $\leq-1.0$ and those with a T-score $>-1.0$. There has been no evidence regarding the influence of denosumab in patients with a $\mathrm{T}$-score $\leq-2.5$ or $>-1.0$ receiving AI treatment. Therefore, further studies examining patients with osteoporosis or normal BMD in consideration of these factors are warranted. We are in the process of conducting a single-arm prospective study (UMINCTR, UMIN000027425) of patients with a T-score classification of $<-2.5$ and a multicenter, randomized, comparative study regarding the efficacy of denosumab in postmenopausal patients with normal BMD and those with a T-score classification of $>-1.0$ receiving adjuvant $\mathrm{AI}$ (ClinicalTrials.gov identifier NCT03324932 and UMIN 000022256).

\section{Conclusion}

Currently, rebound-associated vertebral fracture after discontinuation of denosumab is a critical issue. Therefore, denosumab should not be discontinued as long as AIs are administered, even if patients are osteopenic. In summary, twice-yearly treatment with denosumab was associated with consistently greater gains in BMD among Japanese women receiving adjuvant $\mathrm{AI}$ therapy, regardless of the baseline characteristics or skeletal site. 


\section{Disclosure}

The authors report no conflicts of interest in this work.

\section{References}

1. Kaufmann M, Jonat W, Hilfrich J, et al. Improved overall survival in postmenopausal women with early breast cancer after anastrozole initiated after treatment with tamoxifen compared with continued tamoxifen: the ARNO 95 Study. J Clin Oncol. 2007;25(19):2664-2670.

2. Land SR, Wickerham DL, Costantino JP, et al. Patient-reported symptoms and quality of life during treatment with tamoxifen or raloxifene for breast cancer prevention: the NSABP Study of Tamoxifen and Raloxifene (STAR) P-2 trial. JAMA. 2006;295(23):2742-2751.

3. Breast International Group (BIG) 1-98 Collaborative Group; Thürlimann B, Keshaviah A, et al. A comparison of letrozole and tamoxifen in postmenopausal women with early breast cancer. $N$ Engl J Med. 2005;353(26):2747-2757.

4. Howell A, Cuzick J, Baum M, et al; ATAC Trialists' Group. Results of the ATAC (Arimidex, Tamoxifen, Alone or in Combination) trial after completion of 5 years' adjuvant treatment for breast cancer. Lancet. 2005;365(9453):60-62.

5. Arimidex, Tamoxifen, Alone or in Combination Trialists' Group; Buzdar A, Howell A, et al. Comprehensive side-effect profile of anastrozole and tamoxifen as adjuvant treatment for early-stage breast cancer: long-term safety analysis of the ATAC trial. Lancet Oncol. 2006;7(8):633-643.

6. Coombes RC, Hall E, Gibson LJ, et al; Intergroup Exemestane Study. A randomized trial of exemestane after two to three years of tamoxifen therapy in postmenopausal women with primary breast cancer. $N$ Engl J Med. 2004;350(11):1081-1092.

7. Eastell R, Hannon R. Long-term effects of aromatase inhibitors on bone. J Steroid Biochem Mol Biol. 2005;95(1-5):151-156.

8. Lonning PE, Geisler J, Krag LE, et al. Effects of exemestane administered for 2 years versus placebo on bone mineral density, bone biomarkers, and plasma lipids in patients with surgically resected early breast cancer. J Clin Oncol. 2005;23(22):5126-5137.

9. Nakatsukasa K, Koyama H, Ouchi Y. Effect of denosumab administration on low bone mineral density (T-score -1.0 to -2.5 ) in postmenopausal Japanese women receiving adjuvant aromatase inhibitors for non-metastatic breast cancer. J Bone Miner Metab. Epub 2017 Nov 7.

10. Hadji P. Aromatase inhibitor-associated bone loss in breast cancer patients is distinct from postmenopausal osteoporosis. Crit Rev Oncol Hematol. 2009;69(1):73-82.

11. Eastell R, Hannon RA, Cuzick J, et al; ATAC Trialists' Group. Effect of an aromatase inhibitor on BMD and bone turnover markers: 2-year results of the Anastrozole, Tamoxifen, Alone or in Combination (ATAC) trial (18233230). J Bone Miner Res. 2006;21(8):1215-1223.

12. Eastell R, Adams JE, Coleman RE, et al. Effect of anastrozole on bone mineral density: 5-year results from the anastrozole, tamoxifen, alone or in combination trial 18233230. J Clin Oncol. 2008;26(7):1051-1057.
13. Hadji P, Ziller M, Albert US, Kalder M. Assessment of fracture risk in women with breast cancer using current vs emerging guidelines. Br J Cancer. 2010;102(4):645-650.

14. Coleman RE, Banks LM, Girgis SI, et al; Intergroup Exemestane Study Group. Skeletal effects of exemestane on bone-mineral density, bone biomarkers, and fracture incidence in postmenopausal women with early breast cancer participating in the Intergroup Exemestane Study (IES): a randomised controlled study. Lancet Oncol. 2007;8(2):119-127.

15. Winer EP, Hudis C, Burstein HJ, et al. American Society of Clinical Oncology technology assessment on the use of aromatase inhibitors as adjuvant therapy for postmenopausal women with hormone receptor-positive breast cancer: status report 2004. J Clin Oncol. 2005; 23(3):619-629.

16. Hilner BE, Ingle JN, Chlebowski RT, et al; American Society of Clinical Oncology. American Society of Clinical Oncology 2003 update on the role of bisphosphonates and bone health issues in women with breast cancer. J Clin Oncol. 2003;21(21):4042-4057.

17. National Osteoporosis Foundation. Clinician's guide to prevention and treatment of osteoporosis [cited 2017 Mar 4]. Available from: https://my.nof.org/bone-source/education/clinicians-guide-to-theprevention-and-treatment-of-osteoporosis. Accessed March 4, 2017.

18. Hodgson SF, Watts NB, Bilezikian JP, et al; AACE Osteoporosis Task Force. American Association of Clinical Endocrinologists medical guidelines for clinical practice for the prevention and treatment of postmenopausal osteoporosis: 2001 edition, with selected updates for 2003. Endocr Pract. 2003;9(6):544-564.

19. Tsuboi M, Hasegawa Y, Suzuki S, Wingstrand H, Thorngren KG. Mortality and mobility after hip fracture in Japan: a ten-year follow-up. J Bone Joint Surg Br. 2007;89(4):461-466.

20. Weilbaecher KN, Guise TA, McCauley LK. Cancer to bone: a fatal attraction. Nat Rev Cancer. 2011;11(6):411-425.

21. Lester JE, Dodwell D, Purohit OP, et al. Prevention of anastrozoleinduced bone loss with monthly oral ibandronate during adjuvant aromatase inhibitor therapy for breast cancer. Clin Cancer Res. 2008;14(19):6336-6342.

22. Becker T, Lipscombe L, Narod S, Simmons C, Anderson GM, Rochon PA. Systematic review of bone health in older women treated with aromatase inhibitors for early-stage breast cancer. J Am Geriatr Soc. 2012;60(9):1761-1767.

23. Palermo A, Tuccinardi D, Defeudis G, et al. BMI and BMD: the potential interplay between obesity and bone fragility. Int $J$ Environ Res Public Health. 2016;13(6):E544.

24. Tang SC. Women and bone health: maximizing the benefits of aromatase inhibitor therapy. Oncology. 2010;79(1-2):13-26.

25. Eastell R, Adams JE, Coleman RE, et al. Effect of anastrozole on bone mineral density: 5-year results from the anastrozole, tamoxifen, alone or in combination trial 18233230. J Clin Oncol. 2008;26(7):1051-1058.
Therapeutics and Clinical Risk Management

\section{Publish your work in this journal}

Therapeutics and Clinical Risk Management is an international, peerreviewed journal of clinical therapeutics and risk management, focusing on concise rapid reporting of clinical studies in all therapeutic areas, outcomes, safety, and programs for the effective, safe, and sustained use of medicines. This journal is indexed on PubMed Central, CAS,

\section{Dovepress}

EMBase, Scopus and the Elsevier Bibliographic databases. The manuscript management system is completely online and includes a very quick and fair peer-review system, which is all easy to use. Visit $\mathrm{http}: / /$ www.dovepress.com/testimonials.php to read real quotes from published authors. 